not be used until a plan is submitted to show that confidential AIDS information is secure. The state Department of Health and Rehabilitative Services (HRS) since has adopted a policy to tighten security, prohibiting health workers from taking computers and disks with confidential information home, and putting all files containing confidential information into code.

The issue of using names for HIV and AIDS reporting has been debated hotly over the last decade. Opponents cite two major objections: The first is that illegal violations can occur. Legal violations also can occur. For example, in 1991, the Illinois State Legislature passed a law requiring the state health department to cross-match the AIDS registry against healthcare worker (HCW) licensure records for the purpose of identifying and contacting all HIV-positive HCWs. The mandate never was funded, and so never implemented, but it did pass. Judicial subpoenas also have compromised the security of state and local AIDS registries-no health department can protect itself fully from judicial intervention. The second objection is that namebased reporting requirements may discourage those individuals at the highest risk of infection because of fear of breaches in confidentiality. Studies have shown that people will even cross state lines and do without needed medical and social services when they are afraid of being recorded in a name-based registry. Texas, Maryland, and Oregon already are using unique identifier information, rather than names, for statewide reporting of HIV-related information.
FROM: Landry S, Roche R. Public health specialist said he used AIDS data to screen dates. Tampa Tribune, October 9, 1996.

\section{Draft Guidelines on Infectious Disease and Xenotransplantation}

The US Public Health Service (PHS) has put into the Federal Register, for September 23, 1996, pp 49920ff, a draft PHS "Guideline on Infectious Disease Issues in Xenotransplantation." (Xenotransplantation refers to any procedure that involves the use of live cells, tissues, and organs from a nonhuman animal source that is transplanted into a human or used for ex-vivo perfusion.) The 25-page guideline is retrievable from the Internet at $<$ www.ftp.fda.gov/CBER/gdlns/xeno.txt.> Comments may be sent to the FDA, to the Rockville, Maryland, address shown on the draft document, until December 23, 1996.

Additional news items in this issue: VRE in Liver Transplant Recipients, page 779; Chlamydia Infections Most Common US Notifiable Infectious Disease, page 792; Influenza Vaccine: No Side Effects, page 808; Mediastinitis Associated With HCW Nasal Carriage, page 785; New Test for Diagnosis of CJD, page 797; Intrinsic Contamination Prompts Recall of Albumin, page 802. 